\title{
Why are some people more knowledgeable than others? A longitudinal study of knowledge acquisition
}

\author{
DAVID Z. HAMBRICK \\ Michigan State University, East Lansing, Michigan
}

\begin{abstract}
The purpose of this study was to investigate correlates of knowledge acquisition within a real-world domain-basketball. The study employed a longitudinal design and involved two sessions, with approximately 2.5 months between sessions. Session 1 occurred near the beginning of the men's college basketball season, and Session 2 occurred after the season. There was an indirect effect of interest in basketball on new basketball knowledge, via exposure to domain-relevant information. In addition, prior basketball knowledge had a strong effect on new basketball knowledge distinct from an influence through basketball exposure. This finding suggests that prior knowledge may provide a framework into which new knowledge can be integrated. By contrast, there was no effect of fluid intelligence on new basketball knowledge. Although somewhat surprising given evidence that this aspect of intelligence may play a role in the acquisition of certain types of knowledge, this finding accords with the view that knowledge is a major determinant of various aspects of cognitive functioning, including learning.
\end{abstract}

\begin{abstract}
One of the biggest sources of individual variance in thought is simply knowledge; people know different things. Psychological research on intelligence has tended to ignore this, regarding it as more properly part of the realm of education or sociology. This is a limited view. The role of knowledge must be included in any comprehensive account of individual cognition. (Hunt, 1980, p. 471)
\end{abstract}

Domain knowledge is a powerful predictor of cognitive performance. To illustrate, as compared with novices, experts often have better memory for domain-relevant material, such as chess positions (Chase \& Simon, 1973), bridge hands (Engle \& Bukstel, 1978), circuit diagrams (Egan \& Schwartz, 1979), dance steps (Allard \& Starkes, 1991), and music (Sloboda, 1976). A straightforward interpretation of such novice-expert differences is that domain knowledge facilitates memory for domain-relevant information. Of course, domain knowledge appears to contribute to success in other cognitive tasks as well. For example, Voss, Greene, Post, and Penner (1983) found that domain knowledge was the primary determinant of success at solving ill-structured social science problems, and Spilich, Vesonder, Chiesi, and Voss (1979) and Yekovich, Walker, Ogle, and Thompson (1990) discovered that domain knowledge facilitated comprehension of text with domain-

I am grateful to Tim Salthouse, Randy Engle, Phil Ackerman, Pat Kyllonen, and an anonymous reviewer for helpful comments on earlier versions of this article. I thank Katherine Sheldon, Jenn Miller, Justin Lebiecki, Katie Paquette, Bernadette Lum, and Dan Kuehner for help with data collection and entry. Correspondence concerning this article should be addressed to D. Z. Hambrick, Department of Psychology, Michigan State University, East Lansing, MI 48823 (e-mail: hambric3@ msu.edu). relevant content. More recently, Kellogg (2001) found that domain knowledge facilitated production of narrative prose in a writing task. As a final example, Hambrick, Salthouse, and Meinz (1999) found that knowledge of esoteric words was a near-perfect predictor of success in solving difficult New York Times crossword puzzles. Clearly, then, domain knowledge is "power" in cognitive performance. But why are some people more knowledgeable than others? That is, what are the factors that contribute to individual differences in domain knowledge, which in turn correlate with individual differences in cognitive performance? The goal of this study was to investigate this question.

\section{Individual Differences in Domain Knowledge}

Obviously, exposure to information within a domain is necessary for acquisition of knowledge within that domain: Exposure gives one an opportunity to acquire domain knowledge. To illustrate, in order to acquire knowledge about sports or politics, presumably one must engage in various activities that lead to encountering information about sports or politics, such as reading the newspaper, listening to the radio, or watching television. And in fact, the contribution of exposure to individual differences in knowledge has been amply demonstrated by Stanovich and colleagues. For example, in a study by Stanovich and Cunningham (1993), amount of reading experience was measured indirectly with tests of "print exposure" that assessed familiarity with print media, such as magazines and newspapers. Stanovich and Cunningham (1993) found that print exposure accounted for a large proportion of the variance in cultural knowledge, even after statistically controlling for cognitive ability (see also Stanovich \& Cunningham, 1992; West \& Stanovich, 1991). Research further suggests 
that interests - which may lead to exposure to information within particular domains - contribute to knowledge acquisition. For example, interest in the topic of a text predicts later recall of that text (e.g., Alexander, Jetton, \& Kulikowich, 1995; Alexander, Kulikowich, \& Schulze, 1994), and Rolfhus and Ackerman (1996, 1999) observed correlations between broad vocational interest themes (as described by Holland, 1973) and knowledge of various domains (e.g., "investigative" interest correlated with knowledge of sciences).

Evidence concerning the role of such factors as exposure and interests in knowledge acquisition is important because it suggests that individual differences in knowledge are not merely a by-product of general cognitive ability (e.g., Jensen, 1980). However, from the standpoint of understanding individual differences in domain knowledge, a question that remains is whether there are characteristics of the individual that contribute to the acquisition of domain knowledge above and beyond the opportunity for knowledge acquisition that exposure provides. Stated differently, if it can be assumed that some people acquire more domain knowledge through a given amount of exposure than do other people, why is this so?

The psychometric theory of fluid and crystallized general intelligences provides a framework for considering this question (e.g., Cattell, 1943, 1971). On the one hand, fluid intelligence (or Gf) refers to general cognitive processes, such as reasoning and memory. Typically, Gf is measured with tests that emphasize the efficiency and effectiveness of cognitive processing at the time of assessment-for example, nonverbal tests of reasoning ability such as Raven's Progressive Matrices. Furthermore, recent research has established that Gf is strongly correlated with working memory, which may be defined as the ability to maintain information in an activated and accessible state during ongoing processing (Baddeley \& Hitch, 1974). For example, using structural equation modeling, Kyllonen and Christal (1990) and Kyllonen (1996) reported very strong positive correlations (e.g., $r \mathrm{~s}>.80$ ) between abstract reasoning and working memory (see also Ackerman, Beier, \& Boyle, 2002; Engle, Tuholski, Laughlin, \& Conway, 1999). On the other hand, crystallized intelligence (or Gc) refers to knowledge acquired through experience. Gc is often measured with tests that emphasize breadth of general knowledge. For example, participants might be asked questions such as Who painted the Sistine Chapel? and What is the Koran? and to define words such as audacious and encumber. However, in line with Cattell's (1971) observation that Gc extends into "Protean"-or domain-specificforms during adulthood, Ackerman (1996) proposed that the concept of Gc should be expanded to encompass not only general knowledge, but also domain knowledge acquired through vocational and avocational activities.

A number of theorists have hypothesized that the ability to learn is a primary expression of general intelligenceor psychometric $g$. For example, Woodrow (1921) described intelligence as an "acquiring-capacity" (p. 207), and Hen- mon (1921) proposed that "the intelligent person is capable of readily appropriating information or knowledge" (p. 195). More recently, Jensen (1998) argued that "there is no general learning factor ... that is independent of psychometric g" (p. 276). Consistent with this hypothesis, Gf, which may be synonymous with g (e.g., Gustafsson, 1987, 1988), correlates with general knowledge (e.g., Cattell \& Horn, 1978; Horn \& Cattell, 1966, 1967) and predicts learning outcomes, such as scholastic achievement (see Horn \& Noll, 1997). As articulated by Cattell (1971) in his investment theory of intelligence, one possible interpretation of this evidence is that people with high levels of Gf are better able to acquire knowledge through experience than people with lower levels of Gf. Nonetheless, research suggests that another important factor in the acquisition of knowledge about some domain is what one already knows about that domain - an aspect of Gc. For example, evidence suggests that domain knowledge facilitates learning from text (e.g., Spilich et al., 1979; Yekovich et al., 1990) and acquisition of complex skills (e.g., Kyllonen \& Stephens, 1990; Ree, Caretta, \& Teachout, 1995). In addition, Beier and Ackerman (2001) found that Gc was a better predictor of knowledge of current events than was Gf. It appears, then, that the more one knows about some domain, the easier it is to acquire new knowledge, perhaps because knowledge provides a structure into which new information can be encoded and from which it can be retrieved later (e.g., Ericsson \& Kintsch, 1995).

\section{Present Study}

The primary goal of this study was to investigate the effects of Gf and $\mathrm{Gc}$ aspects of intelligence on acquisition of new domain knowledge within an everyday domain and under naturalistic learning conditions. To date, very few studies have investigated this issue, although there is some relevant evidence. For example, in studies of text-based learning, Walker (1987), Recht and Leslie (1988), Schneider, Körkel, and Weinert (1989), and Schneider, Bjorklund, and Maier-Brückner (1996) all found that prior domain knowledge enhanced learning from passages that contained domain-relevant content. By contrast, effects of various Gf measures on learning were small and nonsignificant in these studies. Similarly, in a study by Britton, Stimson, Stennett, and Gülgöz (1998), domain knowledge had a positive effect on learning from an expository text about the Vietnam War, whereas there was no effect of working memory. McNamara (1998) reported a similar result, using an expository text about heart disease. More recently, however, Hambrick and Engle (2002) found that although prior knowledge of baseball had a strong facilitative effect on memory for information from simulated radio broadcasts of baseball games, there also was a significant (albeit small) effect of working memory. There is also some relevant evidence in the literature on job performance. For example, Ree et al. (1995) evaluated effects of $g$ and prior job knowledge on learning in U.S. Air Force officers enrolled in a pilot training course. There was a 
positive effect of $g$ on initial learning in the course, but thereafter, knowledge already acquired was the strongest predictor of additional learning.

This brief review suggests that although prior domain knowledge seems to facilitate acquisition of new domain knowledge, an unanswered question is whether and to what extent Gf makes an additional predictive contribution. Following what might be considered a traditional approach to research on learning, this question could be investigated by exposing participants to some to-be-learned information in a laboratory task. From the standpoint of understanding individual differences in learning, an advantage of this type of approach is that exposure to the experimental stimuli is controlled. That is, because the participants receive the same exposure to the stimuli during the laboratory session, individual differences in learning can be attributed to factors other than exposure. However, a disadvantage is that conditions of learning may not be the same as those encountered outside of the laboratory (e.g., Neisser, 1978). For example, unlike in the laboratory, learning in the real world is often self-paced and occurs over an extended period of time (months or years). In addition, use of abstract or arbitrary material in laboratory studies of learning precludes examination of potentially important predictors of knowledge acquisition such as prior knowledge and interests.

An alternative, naturalistic research approach attempts to assess memory for information learned outside of the laboratory. For example, in studies of "flashbulb" memory, participants are asked to report their recollection of a noteworthy event, such as the 1963 assassination of John F. Kennedy (Brown \& Kulik, 1977), the 1986 explosion of the space shuttle Challenger (McCloskey, Wible, \& Cohen, 1988), or the 1989 California earthquake (Neisser et al., 1996). Obviously, exposure to such target events is not experimentally controlled. However, because of their significance, it is reasonable to assume that all the participants were exposed to the events, either directly or indirectly. As another example, learning could be assessed in participants who were exposed to some information through a common experience. Using this approach, Bahrick and colleagues (e.g., Bahrick, 1979, 1984; Bahrick \& Hall, 1991; Bahrick \& Phelps, 1987) conducted a series of studies in which long-term retention of information from academic courses was examined (see also Conway, Gardiner, Perfect, Anderson, \& Cohen, 1997).

The study reported here also used a naturalistic research approach. Specifically, through the use of a longitudinal design, the aim of this study was to evaluate predictors of knowledge acquisition within an everyday domain-basketball. However, unlike in previous studies, an assumption was that the participants would differ in exposure to domain-relevant information, and there was no attempt to constrain exposure in any way. For example, the expectation was that individual preferences would lead some participants to favor watching televised games between teams in one particular conference (e.g., Big Ten). Thus, in contrast to the naturalistic studies described ear- lier, which assessed memory for a single event to which all the participants were presumably exposed, the approach in this study was to assess knowledge acquisition in a more broadly defined domain. Men's college basketball was chosen as the domain because intuition suggested that there would be a wide range of exposure to domain-relevant information within a college student sample; in addition, a substantial amount of new knowledge about basketball can be acquired within the relatively short period of time defining a single basketball season.

Session 1 occurred during the 2000-2001 men's college basketball season. During Session 1, the participants completed tests of abstract reasoning ability and working memory to assess Gf, as well as tests of prior (or preexperimental)knowledge of basketball. Session 2 occurred approximately 2.5 months after Session 1 and immediately following the season. During Session 2, the participants completed questionnaires and tests to assess interest in men's college basketball and exposure to basketballrelated information during the 2000-2001 season via such activities as watching television, reading the newspaper, and listening to the radio. The participants also completed tests to assess new knowledge of men's college basketballthat is, knowledge acquired in the interval between Sessions 1 and 2.

I conducted two major sets of analyses. First, I conducted a hierarchical regression analysis to evaluate the main effects and interactions of predictor variables on new basketball knowledge. I predicted that prior basketball knowledge would account for a large proportion of the variance in new basketball knowledge and that basketball interest and basketball exposure would also contribute. This finding would support the hypothesis that prior domain knowledge facilitates acquisition of new domain knowledge, as well as the hypothesis that interests contribute to individual differences in domain knowledge (e.g., Alexander et al., 1994; Alexander, Kulikowich, \& Sharon, 1995; Rolfhus \& Ackerman, 1996, 1999). Another question was whether there also would be a unique effect of Gf on new basketball knowledge. Such an effect would suggest that Gf contributes to individual differences in knowledge, even within narrow real-world domains in which the contribution of prior domain knowledge might be expected to be large. Failure to observe such an effect would be surprising, but this finding would be important because it would suggest that Gf may sometimes play little role in knowledge acquisition. I also evaluated interactions between the predictor variables. In agreement with the hypothesis that people high in Gf acquire more knowledge through a given amount of exposure than do people low in Gf (Cattell, 1971), of particular interest was the possibility of an interaction in the direction of an increasing effect of basketball exposure on new basketball knowledge as a function of increasing Gf.

Second, I used structural equation modeling to evaluate both direct and indirect effects of the predictor variables on new basketball knowledge. In agreement with the idea that interest in a domain leads to exposure to information 
within that domain, I predicted that there would be an indirect effect of basketball interest on new basketball knowledge, via basketball exposure. In addition, I predicted that there would be an effect of prior basketball knowledge on basketball interest: Participants with high levels of prior basketball knowledge would be more interested in basketball during the acquisition interval than participants with lower levels of prior basketball knowledge would be. Furthermore, I predicted that males would report higher levels of basketball interest and, hence, higher levels of basketball exposure, than females, because men's basketball is probably more popular among males than among females. Finally, in line with Ackerman, Bowen, Beier, and Kanfer's (2001) suggestion that interests may partly explain gender differences in knowledge, I predicted that effects of gender on new basketball knowledge would be mediated through basketball interest and basketball exposure. That is, the expectation was that the direct effect of gender on new basketball knowledge would be small relative to the indirect effects through basketball interest and exposure.

\section{METHOD}

\section{Participants}

A total of 187 undergraduate students (56\% female) recruited from the participant pool at a large public university (Michigan State University) participated in Session $1 .{ }^{1}$ Of these participants, 181 (55\% female) returned for Session 2; thus, the return rate was 96.8\%. (Of the 6 participants who did not return for Session 2, 5 were female, and 1 was male.) The participants who completed Sessions 1 and 2 received course credit, as well as a $\$ 10$ bonus for finishing the study. The participants who completed Session 1 but not Session 2 received course credit for the amount of time that they had participated in the study.

\section{Materials and Procedure: Session 1}

Session 1 occurred in a 1-week period during the month of January 2001 and approximately midway through the Division I men's basketball season. After signing an informed consent form, the participants completed (1) a demographic form with questions about age, gender, and ethnicity, (2) a questionnaire with self-rating scales to assess knowledge of men's college basketball and questions about engagement in various basketball-related activities, (3) tests of prior basketball knowledge, and (4) tests of abstract reasoning and working memory to assess Gf. The demographic form and self-rating scales were administered first and second, respectively. The participants next completed the tests of working memory, prior basketball knowledge, and abstract reasoning in the following order: computation span, prior basketball knowledge-1, reading span, prior basketball knowledge-2, Raven's matrices, prior basketball knowledge-3, Shipley abstraction, prior basketball knowledge- 4, ETS letter sets, prior basketball knowledge-5, Cattell classification, and prior basketball knowledge- 6 .

Session 1 lasted approximately $2 \mathrm{~h}$, and an experimenter tested the participants in groups of up to 30 . Upon completion of the session, an experimenter told the participants that they would be contacted at a later date to schedule an appointment for Session 2, during which they would take additional paper-and-pencil tests. Because the experimenter did not tell the participants that they would take tests of newly acquired basketball knowledge, it seems reasonable to argue that the conditions of learning between Sessions 1 and 2 were incidental, rather than intentional.
Self-ratings of basketball knowledge. On 5-point scales, the participants rated their current knowledge of three areas of basketball: (1) rules and terminology, (2) players, teams, and events in men's college basketball, and (3) players, teams, and events in Michigan State men's college basketball. For each knowledge category, the anchor ratings were 1 (very low knowledge) and 5 (very high knowledge). Brief descriptions of each rating were provided. There was no time limit.

Basketball activities. The participants also answered the following questions with a yes or no response: (1) Have you ever played basketball on an organized team? (2) Have you ever coached an organized basketball team of any type? (3) Have you ever collected basketball memorabilia? (4) Do you subscribe to any magazines devoted to basketball? and (5) Do you own any books about basketball? Yes responses were considered indicative of interest in basketball.

Prior basketball knowledge. The participants completed six paper-and-pencil tests to assess prior basketball knowledge. Each test contained 25 multiple-choice (four-alternative) questions. Tests 1 and 4 assessed knowledge of basketball rules and regulationsfor example, What is the maximum amount of time that players are allowed to stand in the free throw lane? (answer, 3 seconds). Tests 2 and 5 assessed knowledge of significant people and events in the history of men's college basketball (i.e., basketball "trivia"), excluding those related to Michigan State basketball-for example, Who was a two-year consensus All-American for Wake Forest in 1996 and 1997? (answer, Tim Duncan). Tests 3 and 6 assessed knowledge of important people and events in Michigan State men's college basketball - for example, Who was the Michigan State head basketball coach for 19 seasons between 1976 and 1995? (answer, Jud Heathcote). The time limit for each test was $6 \mathrm{~min}$, and the participants were encouraged to answer all of the questions even if they had to guess. The score for each test was the number of questions answered correctly. Information for questions came from various books and Internet sites devoted to men's college basketball.

Abstract reasoning. The participants completed four paper-andpencil tests of abstract reasoning. The first test contained half of the items (the 18 odd-numbered items) from Raven's Advanced Progressive Matrices test of abstract reasoning (Raven, 1962). Each problem consisted of a series of geometric patterns in which one pattern (always in the lower right corner of the $3 \times 3$ matrix) was missing. The task was to choose from among six alternatives the pattern that logically completed the series. The time limit was $10 \mathrm{~min}$. The second test was a slightly modified version of the classifications test from the Cattell Culture Fair Test (Scale 2; Institute for Personality and Ability Testing, 1973). Each of the 11 problems consisted of an array of five geometric patterns that could differ in size, orientation, or content. The task was to select the two patterns that differed from the other three. The time limit was 4 min.

The third reasoning test was the abstraction test from the Shipley Institute for Living Scales (Zachary, 1986). Each of the 20 problems consisted of sets of alphanumeric characters, with the final set missing. The task was to write down the characters that would complete the series in the blank spaces provided. The time limit was 5 min. The fourth test was the letter sets test from the ETS Kit of FactorReferenced Cognitive Tests (Ekstrom, French, Harman, \& Derman, 1976). Each item consisted of five letter groups. The task was to identify the letter group that did not belong with the others. The time limit was $7 \mathrm{~min}$. The score for each reasoning test was the number of items answered correctly.

Working memory. The participants completed two tests of working memory developed by Salthouse and Babcock (1990): computation span and reading span. The stimuli in each task were recorded to compact disc by the first author and were presented aurally. Each test took approximately $12 \mathrm{~min}$ to complete. I selected these tests because they have been used in previous studies and appear to provide reliable and valid measures of working memory (e.g., Salthouse, 1993). 
The goal of computation span was to solve simple arithmetic problems while attempting to remember the final digit from each problem. The problems were presented in sets of one to six. There were two trials at each set size, and the trials were presented in an ascending set size order. After each problem (e.g., three plus one equals), the task was to circle the answer to the problem on a response sheet displaying three possible answers (e.g., $2 / 4 / 6$ ). Three seconds were allowed for a response. Once the final problem in a trial had been presented, the participants heard the instruction, "Turn the page and recall the final digit from each problem." At this point, the task was to write down the digits in the order in which they were presented. For example, if the participants had heard four plus two equals followed by three plus six equals in a two-problem trial, the goal would have been to write down 2 and 6 in the provided blanks. Four seconds were allowed for the recall of each digit. Thus, the response time was $4 \mathrm{sec}$ for trials with one problem, $8 \mathrm{sec}$ for trials with two problems, and so forth. For a given trial, the participants were awarded one point per recalled digit if there were no arithmetic mistakes and if the digits were recalled in the correct order. For each trial, credit was awarded only when a set was recalled perfectly, and thus the scoring procedure was conservative. The total score was the sum of scores across trials.

The goal of reading span was to answer questions about simple sentences while attempting to remember the final word from each sentence for later recall. Problems were presented in sets of one to six. There were two trials at each set size, and the trials were presented in an ascending set size order. Immediately after each sentence was presented (e.g., Everyone in the stadium felt cold), the task was to answer a question about the sentence (e.g., Where was everyone?), which appeared on a response sheet with three possible answers (e.g., at home / in the rink / in the stadium). Three seconds were allowed for a response. Once the final sentence in a trial had been presented, the participants heard the instruction, "Turn the page and recall the final word from each sentence." At this point, the task was to write down the final words in the order in which they were presented. For example, if participants heard the sentence The iron gate clanged shut followed by The boy practiced his piano lesson three times a day in a two-sentence trial, the goal would have been to write down shut and day. Four seconds were allowed for the recall of each word. For a given trial, the participants received one point for each recalled word if there were no verification mistakes and if the words were recalled in the correct order. Credit was awarded only for perfectly recalled sets, and the total score was the sum of scores across perfectly recalled sets.

\section{Materials and Procedure: Session 2}

Session 2 occurred in a 1-week period during the month of April 2001, immediately following the end of the men's college basketball season. The participants completed questionnaires and tests to assess interest in basketball and involvement in basketball-related activities during the 2000-2001 season, followed by tests to assess newly acquired basketball knowledge (i.e., acquired between Sessions 1 and 2). Session 2 lasted approximately $1 \mathrm{~h}$, and the participants were tested in groups of up to 30 . The participants were contacted via e-mail or by phone to schedule an appointment for Session 2.

Self-ratings of basketball interest. On 5-point scales, participants rated their interest in four areas of men's college basketball during the 2000-2001 season: (1) Michigan State basketball during the regular season, (2) Michigan State basketball during the NCAA tournament, (3) men's college basketball (excluding Michigan State) during the regular season, and (4) men's college basketball (excluding Michigan State) during the NCAA tournament. For each knowledge category, the anchor ratings were 1 (very low interest) and 5 (very high interest). Descriptions of each rating were provided. There was no time limit.

Basketball exposure. The participants answered seven questions designed to assess exposure to basketball-related information during the 2000-2001 season via engagement in various basketball-related activities. Because intuition suggested that levels of exposure would be greater for some participants during the season-end NCAA basketball tournament than during the regular season, the participants gave two separate estimates for each activity, one reflecting time spent engaging in the activity during the regular season and the other reflecting time spent engaging in the activity during the NCAA tournament. Each question consisted of two parts. First, with a yes or no response, the participant indicated whether he or she had engaged in a particular basketball-related activity during the 2000-2001 men's college basketball season. Second, if the participant gave a yes response, he or she provided an estimate of involvement in the activity.

Question 1 asked for four estimates of number of men's college basketball games attended: Michigan State regular season home games, Michigan State regular season away games, non-Michigan State regular season games, and NCCA tournament games. Question 2 asked for estimates of minutes per week spent watching basketball games on television. Question 3 asked for estimates of minutes per week spent watching programs about men's college basketball (e.g., highlight shows). Question 4 asked for estimates of minutes per week spent reading about basketball in the newspaper. Question 5 asked for estimates of minutes per week spent reading about basketball on the Internet. Question 6 asked for estimates of minutes per week spent having conversations about basketball. Question 7 asked for estimates of minutes per week spent listening to basketball games on the radio. For presentation of the results, all the estimates are expressed in hours per week. There was no time limit for the basketball experience questionnaire, but most of the participants finished in 10-20 min.

I developed two other paper-and-pencil tests to assess basketball exposure. These tests used a recognition-based format to assess exposure developed by Stanovich and colleagues (e.g., Stanovich \& Cunningham, 1993). First, in the commentator recognition test, the participants were given a list of 90 names, with a blank space to the left of each name. Half of the names were of actual basketball commentators (e.g., Dick Vitale, Lesley Visser), whereas the other half of the names were foils (e.g., Bruce Burns, Dave Madden). The task for the participants was to place checkmarks next to the names of people they knew to be actual basketball commentators. An experimenter instructed the participants not to guess, because they would be penalized for incorrect answers. Second, in the magazine recognition test, the participants were given a list of 22 possible titles of magazines. Half of the titles were of actual magazines that cover basketball (e.g., Basketball Digest, Sporting News), whereas the other half of the titles were foils (e.g., The Basketball Report, Sports Zone). The reasoning behind these tests was that people with high levels of basketball exposure would be more familiar with basketball commentators and sports magazines (sources of information about basketball) than would people with lower levels of basketball exposure and that the recognition tests would not be susceptible to the problems with inaccurate memory that are possible with retrospective, self-report estimates of exposure. The score on each test was the number of correct answers minus the number of incorrect answers (to correct for guessing). There was no time limit for either test, but most of the participants completed each in under $5 \mathrm{~min}$.

New basketball knowledge. There were six paper-and-pencil tests designed to assess knowledge of men's college basketball acquired between Sessions 1 and 2. Each test contained 35 multiple-choice (four-alternative) questions, and the questions pertained only to information about people and events in men's college basketball that was disseminated during the 74-day period spanning from January 19, 2001 (the day after the last possible participation date for Session 1) to April 2, 2001 (3 days prior to the first possible participation date for Session 2).

Tests 1 and 4 assessed newly acquired knowledge of Michigan State men's basketball. Half of the questions on these tests pertained to the regular season-for example, During the regular season, what 
Big Ten team defeated Michigan State and Illinois, both highly ranked teams? (answer, Ohio State). The other half of the questions pertained to the NCAA tournament-for example, What team did Michigan State defeat in the first round of the NCAA tournament? (answer, Alabama State). Tests 2, 3, 5, and 6 assessed new knowledge of men's college basketball, excluding Michigan State. Half of the questions on these tests pertained to the regular season-for example, During the regular season, which team remained undefeated for the longest with 20 wins? (answer, Stanford). The other half of the questions pertained to the season-end NCAA tournament-for example, What team won the NCAA national championship this year? (answer, Duke). For each test, the score was the number of questions answered correctly. Information for the questions was obtained from three Internet sites that provide daily coverage of men's college basketball (www.espn.com, www.cnnsi.com, and www.sportingnews. com). I obtained information for questions about Michigan State from these two Internet sites, from the Michigan State Internet site (www.msu.edu), and from two newspapers, the Lansing State Journal and Michigan State's The State News.

The questions on these tests were written so that it would be difficult, if not impossible, for the participants with high levels of prior basketball knowledge to answer the questions correctly without having been exposed to the queried information. For example, one question asked, Trailing by 10 points with less than 1 minute to play, Duke made a miraculous comeback and eventually defeated this team in overtime. Maryland is the answer, but each of the incorrect alternatives (Virginia, North Carolina, and Wake Forest) was plausible, particularly because all of the teams are in the same collegiate conference. Another question asked, What team did Michigan State defeat in the first round of the NCAA tournament? Obviously, the participants would not know that Alabama State is the answer to this question unless they were exposed to this information. As a final example, the participants were asked, What Duke player was sidelined late in the regular season because of a broken bone in his right foot? Given that the incorrect alternatives (Shane Battier, Jason Williams, and Chris Duhon) were important players on Duke's team, it is unlikely that participants could have correctly guessed Carlos Boozer by using prior basketball knowledge. In short, although it is possible that prior basketball knowledge enabled correct guessing on some questions, it seems reasonable to assume that most of the questions on the tests of new basketball knowledge tapped newly acquired knowledge.

\section{RESULTS}

There were four missing observations in the data set; these observations were replaced with total sample means. In addition, 10 participants did not follow instructions in the computation span test. (In particular, these participants attempted to recall the solution to each arithmetic problem instead of the final digit.) The data for these participants were discarded. Thus, a total of 171 participants contributed complete and usable data. Power analyses revealed that a sample of 171 would provide adequate statistical power $(1-B>.80)$ to detect small-to-medium effects of

Table 1

Descriptive Statistics for Basketball (BB) Self-Ratings (Interest and Knowledge) and Exposure Variables by Gender

\begin{tabular}{|c|c|c|c|c|c|c|}
\hline \multirow[b]{2}{*}{ Variable } & \multicolumn{2}{|c|}{ Male $(n=76)$} & \multicolumn{2}{|c|}{$\underline{\text { Female }(n=95)}$} & \multirow[b]{2}{*}{$t$} & \multirow[b]{2}{*}{$d$} \\
\hline & $M$ & $S D$ & $M$ & $S D$ & & \\
\hline \multicolumn{7}{|l|}{ Self-ratings of prior BB knowledge (Session 1) } \\
\hline Prior BB Knowledge 1 (rules and terminology) & 3.91 & 0.88 & 3.21 & 1.00 & $4.83^{* *}$ & .69 \\
\hline Prior BB Knowledge 2 (NCAA players, teams, and events) $\dagger$ & 2.92 & 1.08 & 2.31 & 0.76 & $4.21 * *$ & .63 \\
\hline Prior BB Knowledge 3 (MSU players, teams, and events) & 3.09 & 1.06 & 2.75 & 0.94 & $2.25^{*}$ & .33 \\
\hline \multicolumn{7}{|l|}{ Proportion yes on BB activity questions (Session 1) } \\
\hline Played BB on an organized team? $\dagger$ & .71 & .46 & .44 & .50 & $3.84 * *$ & .54 \\
\hline Coached an organized BB team? $\dagger$ & .12 & .33 & .07 & .25 & 1.26 & .17 \\
\hline Collected BB memorabilia? $\dagger$ & .59 & .50 & .25 & .43 & $4.88^{* *}$ & 69 \\
\hline Subscribed to magazines about $\mathrm{BB} ? \dagger$ & .06 & .24 & .02 & .14 & 1.41 & .20 \\
\hline Own books about BB? $\dagger$ & .33 & .43 & .10 & .31 & $3.73 * *$ & .56 \\
\hline \multicolumn{7}{|l|}{ Self-ratings of BB interest (Session 2) } \\
\hline BB Interest 1 (MSU regular season) & 3.55 & 1.16 & 2.77 & 1.05 & $4.64 * *$ & 67 \\
\hline BB Interest 2 (MSU postseason) & 4.14 & 1.08 & 3.58 & 1.05 & $3.46^{* *}$ & .51 \\
\hline BB Interest 3 (Other NCAA regular season) $\dagger$ & 2.84 & 1.22 & 1.85 & 0.87 & $6.16^{* *}$ & .86 \\
\hline BB Interest 4 (Other NCAA postseason) & 3.62 & 1.26 & 2.61 & 1.18 & $5.38 * *$ & .77 \\
\hline \multicolumn{7}{|l|}{ BB exposure (Session 2) } \\
\hline No. games attended $\dagger$ & 3.36 & 6.10 & 1.88 & 4.31 & 1.78 & .28 \\
\hline TV games $\dagger$ & 8.96 & 8.59 & 5.32 & 5.62 & $3.19 * *$ & .50 \\
\hline TV other $\dagger$ & 2.16 & 2.83 & 0.69 & 1.09 & $4.28 * *$ & 67 \\
\hline $\operatorname{Read} \dagger$ & 0.67 & 0.97 & 0.42 & 0.56 & $2.02 *$ & .32 \\
\hline Internet $\dagger$ & 0.56 & 0.84 & 0.09 & 0.30 & $4.65^{* *}$ & .73 \\
\hline Conversation $\dagger$ & 1.76 & 1.95 & 0.78 & 0.73 & $4.17 * *$ & .66 \\
\hline Radio & 0.23 & 0.57 & 0.28 & 0.69 & -0.43 & -.08 \\
\hline Commentator recognition $\dagger$ & 9.67 & 9.35 & 1.76 & 3.52 & $6.99 * *$ & 1.01 \\
\hline Magazine recognition $\dagger$ & 2.39 & 1.52 & 1.58 & 1.08 & $3.94 * *$ & .60 \\
\hline
\end{tabular}

Note- ${ }^{\dagger}$ denotes that an adjusted $t$ statistic is reported because Levine's test indicated unequal variances for males and females; $d=$ Cohen's effect size. Knowledge rating scale: 1 (very low knowledge), 2 (low knowledge), 3 (average knowledge), 4 (high knowledge), and 5 (very high knowledge). Interest rating scale: 1 (very low interest), 2 (low interest), 3 (average interest), 4 (high interest), and 5 (very high interest). NCAA, National Collegiate Athletic Association; No. games attended, number of men's college BB games attended; TV games, hours per week watching BB games on TV; TV other, hours per week watching programs about BB on TV; Read, hours per week reading about BB; Internet, hours per week reading about BB on the Internet; Conversation, hours per week having conversations about BB; Radio, hours per week listening to BB games on the radio. $* p<.05$. **p $p<.01$. 
Table 2

Descriptive Statistics and Correlation Matrix

\begin{tabular}{|c|c|c|c|c|c|c|c|c|c|c|c|c|c|c|c|c|c|}
\hline & 1 & 2 & 3 & 4 & 5 & 6 & 7 & 8 & 9 & 10 & 11 & 12 & 13 & 14 & 15 & 16 & 17 \\
\hline \multicolumn{18}{|l|}{ Gf } \\
\hline 1. Raven's mat. & $(.70)$ & .36 & .29 & .19 & .23 & .21 & -.01 & -.03 & -.03 & .06 & -.04 & -.02 & .08 & .02 & .00 & .06 & -.07 \\
\hline 2. Cattell class. & & $(.60)$ & .36 & .28 & .32 & .24 & -.03 & -.01 & -.06 & .14 & .10 & .02 & .11 & -.01 & .00 & .12 & .07 \\
\hline 3. Shipley abs. & & & $(.43)$ & .42 & .34 & .39 & .08 & -.02 & -.01 & .05 & .05 & .03 & .11 & .07 & .03 & .10 & .13 \\
\hline 4. Letter sets & & & & $(.64)$ & .24 & .25 & .13 & .07 & .04 & .12 & .03 & .04 & .15 & .04 & .02 & .11 & .08 \\
\hline 5. Comp. span & & & & & $(.69)$ & .50 & .12 & .14 & .07 & .25 & .32 & .18 & .26 & .23 & .11 & .16 & .15 \\
\hline 6. Read. span & & & & & & $(.62)$ & .08 & .02 & .05 & .07 & .11 & .07 & .08 & .11 & .01 & .07 & -.04 \\
\hline \multicolumn{18}{|l|}{ Prior BB Knowledge } \\
\hline 7. Prior BB Know. $1 *$ & & & & & & & - & .55 & .48 & .70 & .52 & .58 & .70 & .51 & .58 & .23 & .31 \\
\hline 8. Prior BB Know. 2* & & & & & & & & - & .78 & .62 & .55 & .70 & .57 & .61 & .74 & .39 & .44 \\
\hline 9. Prior BB Know. $3 *$ & & & & & & & & & - & .51 & .43 & .67 & .42 & .52 & .67 & .45 & .47 \\
\hline 10. Prior BB Know. 1 & & & & & & & & & & $(.83)$ & .69 & .74 & .81 & .68 & .73 & .28 & .51 \\
\hline 11. Prior BB Know. 2 & & & & & & & & & & & $(.83)$ & .71 & .65 & .80 & .71 & .30 & .45 \\
\hline 12. Prior BB Know. 3 & & & & & & & & & & & & $(.80)$ & .66 & .74 & .83 & .42 & .50 \\
\hline 13. Prior BB Know. 4 & & & & & & & & & & & & & $(.85)$ & .62 & .65 & .22 & .42 \\
\hline 14. Prior BB Know. 5 & & & & & & & & & & & & & & $(.82)$ & .70 & .35 & .43 \\
\hline 15. Prior BB Know. 6 & & & & & & & & & & & & & & & $(.81)$ & .38 & .51 \\
\hline \multicolumn{18}{|l|}{ BB Exposure } \\
\hline 16. No. games att. $\dagger$ & & & & & & & & & & & & & & & & - & .39 \\
\hline 17. TV games $\mathrm{h} / \mathrm{wk} \dagger$ & & & & & & & & & & & & & & & & & - \\
\hline 18. TV other $\mathrm{h} / \mathrm{wk} \dagger$ & & & & & & & & & & & & & & & & & \\
\hline 19. Read h/wk $\dagger$ & & & & & & & & & & & & & & & & & \\
\hline 20. Internet $\mathrm{h} / \mathrm{wk} \dagger$ & & & & & & & & & & & & & & & & & \\
\hline 21. Convers $\mathrm{h} / \mathrm{wk} \dagger$ & & & & & & & & & & & & & & & & & \\
\hline 22. Radio h/wk $\dagger$ & & & & & & & & & & & & & & & & & \\
\hline 23. Commentator rec. & & & & & & & & & & & & & & & & & \\
\hline 24. Magazine rec. & & & & & & & & & & & & & & & & & \\
\hline \multicolumn{18}{|l|}{ BB Interest } \\
\hline \multicolumn{18}{|l|}{ 25. BB Int. 1} \\
\hline \multicolumn{18}{|l|}{ 26. BB Int. 2} \\
\hline \multicolumn{18}{|l|}{ 27. BB Int. 3} \\
\hline \multicolumn{18}{|l|}{ 28. BB Int. 4} \\
\hline \multicolumn{18}{|l|}{ New BB Knowledge } \\
\hline \multicolumn{18}{|l|}{ 29. New BB Know. 1} \\
\hline \multicolumn{18}{|l|}{ 30. New BB Know. 2} \\
\hline \multicolumn{18}{|l|}{ 31. New BB Know. 3} \\
\hline \multicolumn{18}{|l|}{ 32. New BB Know. 4} \\
\hline \multicolumn{18}{|l|}{ 33. New BB Know. 5} \\
\hline \multicolumn{18}{|l|}{ 34. New BB Know. 6} \\
\hline 35. Gender & & & & & & & & & & & & & & & & & \\
\hline$M$ & 9.96 & 7.27 & 15.84 & 11.69 & 24.40 & 21.55 & 3.52 & 2.58 & 2.90 & 14.33 & 8.23 & 12.26 & 15.28 & 8.76 & 13.06 & 0.11 & 2.24 \\
\hline$S D$ & 3.05 & 2.35 & 1.71 & 2.20 & 9.47 & 8.96 & 1.01 & 0.96 & 1.01 & 5.23 & 4.98 & 5.25 & 5.21 & 4.73 & 5.32 & 0.18 & 1.38 \\
\hline
\end{tabular}

Note-*Self-rating. $\dagger$ Square-root transformed. Correlations greater than or equal to an absolute value of .19 are significant $(p<.05)$.

predictor variables (e.g., $R^{2} \mathrm{~s}=.02$ ). The length of the interval between Session 1 and Session 2 ranged from 76 to 92 days $(M=82.30, S D=3.41)$. However, I excluded this variable from subsequent analyses because it had no effect on new basketball knowledge.

\section{Characteristics of Sample}

Table 1 displays descriptive statistics for the self-ratings of prior basketball knowledge and basketball interest. Because of the possibility that levels of basketball interest and exposure would differ for the males and the females in this sample, the descriptive statistics are reported by gender. The expectation was that the participants would represent a wide range of knowledge about and interest in men's college basketball. Inspection of Table 1 confirms this expectation: Means for the self-ratings of prior basketball knowledge and basketball interest were neither extremely high nor extremely low, and all of the standard de- viations were close to one. Note also that males gave higher ratings of both prior basketball knowledge and basketball interest than did females and that males were more likely than females to answer yes to three of the five questions about basketball-related activities ( $p<.05$ for all $t \mathrm{~s}$ ). Effect sizes $(d \mathrm{~s})$ for gender were generally medium or larger ( $\geq .50$; Cohen, 1988).

The participants provided two self-report estimates of basketball exposure for various domain-relevant activities, one reflecting time spent engaging in the activity during the regular season and the other reflecting time spent engaging in the activity during the NCAA tournament. However, because the two variables for all but one activity (listening to games on the radio) were strongly correlated (see the Appendix), I summed the variables to form a single variable. Also, except for Michigan State regular season home games, very few participants reported attending basketball games. Thus, I summed the four variables representing 
Table 2

(Continued)

\begin{tabular}{|c|c|c|c|c|c|c|c|c|c|c|c|c|c|c|c|c|c|}
\hline 18 & 19 & 20 & 21 & 22 & 23 & 24 & 25 & 26 & 27 & 28 & 29 & 30 & 31 & 32 & 33 & 34 & 35 \\
\hline .00 & -.07 & .03 & -.08 & .12 & .03 & .19 & -.02 & -.02 & -.07 & .06 & .07 & -.01 & .05 & -.06 & .02 & .00 & .02 \\
\hline-.08 & .02 & -.04 & .02 & .06 & .03 & .08 & .03 & .03 & .00 & .05 & .07 & -.01 & .06 & .04 & .06 & -.01 & -.11 \\
\hline .04 & .03 & -.02 & .09 & .06 & .09 & .10 & .03 & .09 & .05 & .13 & .06 & .14 & .13 & .13 & .14 & .15 & .02 \\
\hline .11 & .13 & .08 & .14 & .03 & .05 & .02 & .11 & .03 & .12 & .16 & .06 & .08 & .12 & .16 & .05 & .06 & -.02 \\
\hline .17 & .10 & .09 & .13 & .02 & .23 & .23 & .17 & .20 & .16 & .27 & .22 & .13 & .22 & .21 & .19 & .29 & -.24 \\
\hline .11 & .02 & .09 & .08 & -.03 & .02 & .19 & .02 & .06 & .01 & .09 & .04 & -.02 & .01 & .04 & .03 & .10 & .04 \\
\hline .43 & .41 & .34 & .41 & .08 & .51 & .25 & .48 & .42 & .53 & .52 & .51 & .50 & .60 & .54 & .58 & .54 & -.35 \\
\hline \multirow[t]{2}{*}{.50} & .45 & .53 & .46 & .17 & .66 & .28 & .63 & .53 & .69 & .64 & .66 & .65 & .64 & .67 & .61 & .69 & -.32 \\
\hline & & .40 & .44 & .20 & .54 & .23 & .59 & .50 & .56 & .54 & .59 & .51 & .49 & .59 & .48 & .55 & -.17 \\
\hline .55 & .37 & .44 & .48 & .09 & .68 & .37 & .59 & .50 & .62 & .62 & .73 & .66 & .71 & .68 & .68 & .68 & -.54 \\
\hline .51 & .29 & .46 & .41 & -.01 & .83 & .39 & .46 & .39 & .57 & .54 & .68 & .69 & .69 & .56 & .61 & .74 & -.60 \\
\hline .58 & .42 & .57 & .49 & .17 & .75 & .38 & .62 & .50 & .61 & .58 & .76 & .69 & .72 & .69 & .66 & .74 & -.45 \\
\hline .48 & .32 & .38 & .41 & .10 & .65 & .37 & .50 & .42 & .52 & .56 & .66 & .62 & .62 & .63 & .63 & .66 & -.54 \\
\hline .52 & .41 & .53 & .40 & .11 & .84 & .46 & .52 & .37 & .59 & .53 & .66 & .68 & .67 & .58 & .60 & .74 & -.52 \\
\hline .58 & .41 & .54 & .45 & .13 & .73 & .39 & .61 & .54 & .65 & .63 & .79 & .76 & .75 & .76 & .73 & .79 & -.41 \\
\hline .34 & .43 & .36 & .33 & .08 & .43 & .16 & .48 & .36 & .40 & .31 & .48 & .42 & .39 & .44 & .37 & .42 & -.12 \\
\hline .57 & .43 & .42 & .52 & .16 & .48 & .21 & .56 & .60 & .47 & .65 & .56 & .55 & .50 & .58 & .55 & .53 & -.25 \\
\hline \multirow[t]{17}{*}{-} & .36 & .55 & .60 & .15 & .52 & .28 & .60 & .58 & .60 & .60 & .59 & .58 & .55 & .58 & .56 & .61 & -.36 \\
\hline & - & .39 & .46 & .12 & .30 & .11 & .55 & .50 & .46 & .43 & .42 & .36 & .35 & .46 & .32 & .42 & -.14 \\
\hline & & - & .45 & .19 & .56 & .36 & .50 & .38 & .55 & .50 & .56 & .58 & .63 & .50 & .57 & .66 & -.40 \\
\hline & & & - & .16 & .36 & .13 & .54 & .55 & .54 & .52 & .55 & .48 & .42 & .50 & .42 & .55 & -.32 \\
\hline & & & & - & .13 & .08 & .17 & .17 & .11 & .12 & .18 & .13 & .10 & .21 & .16 & .09 & .06 \\
\hline & & & & & - & .44 & .50 & .38 & .61 & .53 & .70 & .71 & .73 & .61 & .65 & .79 & -.51 \\
\hline & & & & & & - & .28 & .17 & .28 & .21 & .34 & .39 & .33 & .25 & .31 & .42 & -.30 \\
\hline & & & & & & & - & .75 & .81 & .73 & .68 & .59 & .56 & .68 & .53 & .59 & -.34 \\
\hline & & & & & & & & - & .62 & .76 & .57 & .53 & .49 & .66 & .53 & .52 & -.26 \\
\hline & & & & & & & & & - & .78 & .67 & .62 & .62 & .62 & .58 & .67 & -.43 \\
\hline & & & & & & & & & & - & .64 & .61 & .61 & .65 & .61 & .63 & -.38 \\
\hline & & & & & & & & & & & (.88) & .79 & .76 & .79 & .72 & .79 & -.48 \\
\hline & & & & & & & & & & & & (.83) & .76 & .77 & 80 & .81 & -.46 \\
\hline & & & & & & & & & & & & & (.78) & .74 & .83 & .80 & -.52 \\
\hline & & & & & & & & & & & & & & (.84) & .75 & .73 & -.38 \\
\hline & & & & & & & & & & & & & & & (.85) & .78 & -.43 \\
\hline & & & & & & & & & & & & & & & & (.85) & -.49 \\
\hline 0.81 & 0.53 & 0.28 & 0.94 & 0.24 & 5.27 & 1.94 & 3.12 & 3.83 & 2.29 & 3.06 & 19.24 & 17.19 & 14.45 & 16.88 & 18.85 & 15.23 & 0.56 \\
\hline 0.82 & 0.50 & 0.47 & 0.58 & 0.45 & 7.81 & 1.35 & 1.16 & 1.10 & 1.15 & 1.31 & 7.05 & 6.40 & 5.48 & 5.15 & 6.64 & 6.57 & 0.50 \\
\hline
\end{tabular}

games attended to form a single variable. Inspection of the data revealed that the self-report basketball exposure variables departed from normality (average skewness $=4.92$; average kurtosis $=37.39$ ). This was because there was a high number of small values relative to large values and because there were several outliers.

Data preparation. Because variables with nonnormal distributions can distort the results of structural equation analyses, I took two steps to normalize the self-report basketball exposure variables. The first step was to identify and eliminate possible outliers. Toward this end, I computed a Cook's $D$ statistic for each participant by regressing each variable onto a composite variable reflecting new basketball knowledge, created by averaging $z$ scores for all of the variables representing this construct. ${ }^{2}$ There were three outliers, and I replaced these values with total sample means. Table 1 displays descriptive statistics for the basketball exposure variables with outliers eliminated. As is shown, the participants represented a wide range of basketball exposure, and males tended to report higher levels of exposure than did females. The second step was to perform a squareroot transformation on each self-report exposure variable. The resulting distributions had acceptable skewness (average $=1.06)$ and kurtosis (average $=1.13$ ) values (e.g., skewness $<3$ and kurtosis $<10$ ). (See Kline, 1998, for a discussion of data preparation in structural equation modeling.) For this reason, I used the transformed variables in all subsequent analyses; the results pertaining to basketball exposure reported in Tables 2-4 and in Figure 1 are based on the transformed variables.

\section{Psychometric Properties of Variables}

Table 2 summarizes descriptive statistics and correlations for the predictor and criterion variables. The values in parentheses along the diagonal are reliability estimates (i.e., internal consistency estimates). Three points are noteworthy. 
First, although some of the reliability estimates were not particularly impressive, only one variable (Shipley abstraction) had what might be considered poor reliability (.43). It was not possible to directly compute reliability estimates for the self-report basketball exposure variables, but except for hours per week listening to the radio, these variables correlated moderately with each other and with other variables, suggesting that they were reliable. I eliminated the radio variable from subsequent analyses because of the possibility that it had poor reliability.

Second, suggestive of construct validity, there were medium-to-large correlations among variables representing the hypothesized constructs: Gf (average $r=.29$ ), prior basketball knowledge (average $r=.71$ ), basketball interest (average $r=.74$ ), basketball exposure (average $r=.45$ ), and new basketball knowledge (average $r=.78$ ). Correlations among the $\mathrm{Gf}$ measures were somewhat lower than expected, perhaps because of restriction of range due to the fact that the sample consisted only of college students. In addition, the tests of Gf were speeded, and thus it is possible that they were too short for high reliabilities (e.g., >.80). However, the Gf intercorrelations were still generally medium in magnitude ( $\geq .20$; Cohen, 1988), and all were positive and significant (range $=.19-.50$ ).

Third, the self-report basketball exposure variables correlated positively with both the commentator recognition (average $r=.44$ ) and the magazine recognition (average $r=.18$ ) variables. This finding supports the argument that the self-report estimates of engagement in basketballrelated activities had some degree of validity, given that the recognition-based tests were not susceptible to invalid selfreport estimates, due to inaccurate memory. See Stanovich and Cunningham (1993) for further discussion of the logic of a recognition-based methodology in assessing exposure.

\section{Hierarchical Regression Analyses}

To reiterate, the goal of this study was to investigate correlates of knowledge acquisition within the domain of basketball. To address this goal, I first conducted a hierarchical regression analysis. For use in this analysis, I created unit-weighted composite variables by averaging $z$ scores of the variables reflecting each predictor construct, as well as a unit-weighted composite variable for new basketball knowledge. The self-ratings of prior basketball knowledge were not used in this or subsequent analyses, because they correlated very highly with the objective measures of this construct (cf. Table 2) and were thus considered redundant. I then conducted a hierarchical regression analysis involving three steps. I entered gender in Step 1 to control for its relation with variables in subsequent steps, the composite variables for Gf and the three basketball-related constructs (prior knowledge, interest, and the square root of exposure) in Step 2 to test for main effects of these variables, and cross-product terms representing all possible two-way interactions between these variables in Step 3. For each step, I report the increment in variance accounted for (Inc. $R^{2}$ ), which reflects the proportion of variance collectively accounted for by the variables in that step, and the squared semipartial correlation $\left(s r^{2}\right)$ for each predic- tor variable, which reflects the proportion of variance uniquely accounted for by that variable (Cohen \& Cohen, 1983). Note that the $s r^{2}$ s within Steps 2 and 3 sum to less than the respective steps' $R^{2}$ values, because some variance accounted for by the predictor variables was shared rather than unique (cf. Cohen \& Cohen, 1983; Pedhazur, 1997).

The results are summarized in Table 3. Gender (Step 1) accounted for $26.1 \%$ of the variance in new basketball knowledge. Males outscored females on the tests of new basketball knowledge. Gf and the basketball-related variables (Step 2) accounted for an additional $54.8 \%$ of the variance, but only the effects of the latter variables were significant: prior basketball knowledge $\left(s r^{2}=.147\right)$, basketball interest $\left(s r^{2}=.012\right)$, and basketball exposure $\left(s r^{2}=.007\right)$. Note, however, that only prior basketball knowledge had a substantial independent effect on new basketball knowledge. By contrast, the effect of Gf was nonsignificant $\left(s r^{2}=.000\right)$. The interaction terms (Step 3) accounted for an additional $2.1 \%$ of the variance in new basketball knowledge. Three interactions were statistically significant: $\mathrm{Gf} \times$ basketball interest $\left(s r^{2}=.006\right), \mathrm{Gf} \times$ basketball exposure $\left(s r^{2}=.008\right)$ and prior basketball knowledge $\times$ basketball interest $\left(s r^{2}=.010\right)$. However, these results should be interpreted cautiously, because the interactions were very small. Furthermore, only one was interpretable in light of a priori speculation: The correlation between basketball exposure and new basketball knowledge was stronger at high levels of Gf (e.g., $r=.82$ for $\geq 75$ th percentile) than at lower levels (e.g., $r=.64$ for $\leq 25$ th percentile). This finding is possibly consistent with the hypothesis that people high in Gf acquire more knowledge through exposure than do people low in Gf (e.g., Cattell, 1971). The two other interactions were in the direction of a stronger correlation between basketball interest and new basketball knowledge at low levels of Gf than at higher levels ( $\mathrm{Gf} \times$ basketball interest) and a weaker correlation between prior basketball knowledge and new basketball knowledge at low and high levels of basketball interest than at moderate levels (prior basketball knowledge $\times$ basketball interest). Again, however, the interactions should be interpreted cautiously, because they were very small, accounting for $1 \%$ of the variance or less.

Additional analyses. As was explained earlier, the questions on the tests of new basketball knowledge were not limited to information to which presumably all the participants had been exposed. Nevertheless, it is reasonable to assume that a very high percentage of the participants had been exposed to a certain subset of the queried information. In particular, there was intense media coverage of Michigan State's five games in the 2001 NCAA tournament (vs. Alabama State, Fresno State, Gonzaga, Temple, and Arizona). Each game was televised, broadcast on the radio, reported in local newspapers, and so forth, and there was a great deal of interest in these games in the local community, particularly because Michigan State won the national championship in 2000 and was highly ranked throughout the 2001 season. The tests of new basketball knowledge included at least two questions about each of 
Table 3

Results of Hierarchical Regression

Analysis Predicting New Basketball (BB) Knowledge

\begin{tabular}{lcrrrr}
\hline & Inc. $R^{2}$ & $F$ value & $B$ & $t$ value & $s r^{2}$ \\
\hline Step 1 & .261 & 59.67 & & & \\
Gender & & & -.923 & $-7.73^{* *}$ & .261 \\
Step 2 & .548 & 118.10 & & & \\
Gf & & & .001 & 0.20 & .000 \\
Prior BB knowledge & & .644 & $11.07^{* *}$ & .147 \\
BB interest & & .162 & $2.75^{* *}$ & .012 \\
BB exposure & .021 & 3.23 & .220 & $3.08^{* *}$ & .007 \\
Step 3 & & & .072 & .81 & .001 \\
Gf $\times$ prior BB knowledge & & & -.206 & $-2.32^{*}$ & .006 \\
Gf $\times$ BB interest & & & .289 & $2.64^{* *}$ & .008 \\
Gf $\times$ BB exposure & & & .226 & $3.07^{* *}$ & .010 \\
Prior BB knowledge $\times$ BB interest & & & -.142 & -1.92 & .004 \\
Prior BB knowledge $\times$ BB exposure & & & -.118 & -1.52 & .003 \\
BB interest $\times$ BB exposure & & &
\end{tabular}

Note-Inc. $R^{2}$, increment in variance accounted for; $B$, unstandardized regression coefficient; $s r^{2}$, squared semipartial correlation. ${ }^{*} p<.05 . \quad{ }^{* *} p<.01$.

the tournament games-Who was the opponent? and What was the final score $?^{3}$ For each game, I summed the dichotomous variables (correct or incorrect) for these two questions to create a single variable (therefore, scores ranged from 0 to 2). In addition, I summed the five new variables to create a variable reflecting overall knowledge of the five tournament games. I then entered each variable into a regression equation as a criterion variable, with gender (Step 1), Gf, prior basketball knowledge, and basketball interest (Step 2) as predictor variables. The results are displayed in Table 4, and it is evident that even for information to which perhaps nearly all the participants had received some exposure, the domain-specific variables had the greatest influence on learning. For example, prior basketball knowledge and basketball interest accounted for 7.0\% and $6.8 \%$ of the variance in the overall variable, respectively, whereas the contribution of Gf was negligible $(0.1 \%)$.

\section{Structural Equation Analyses}

Next, I conducted structural equation analyses to evaluate direct and indirect predictors of new basketball knowledge. Two steps were involved.
The first step was to perform confirmatory factor analyses to see whether the intended constructs were measured. In each analysis, I used the covariance matrix as input but present standardized solutions, and I scaled the latent variables by fixing the factor loading of one variable per construct to 1.0. I compared three possible predictor-side measurement models (see Table 5). Each model included separate basketball interest and basketball exposure variables, as well as a Gf variable with loadings from the four reasoning variables and two working memory variables. The models differed in the number of variables representing prior basketball knowledge. The fit of a model (Model 1) with a single prior knowledge variable was acceptable $\left[\chi^{2}(203)=451.69, \chi^{2} / d f=2.23, C F I=.91, N N F I=.90\right.$, $S R M R=.06]$. However, a model (Model 2) with separate but correlated prior knowledge variables (rules/regulations and people/events) provided a better fit $\left[\chi^{2}(199)=\right.$ $363.73, \chi^{2} / d f=1.83, C F I=.93, N N F I=.91, S R M R=$ .06]. This improvement in fit relative to Model 1 was significant $\left[\Delta \chi^{2}(4)=87.96, p<.001\right]$. The fit of a model (Model 3) with one variable for rules/regulations knowledge and two variables for people/events knowledge

Table 4

Results of Hierarchical Regression Analyses Predicting Memory for Michigan State NCAA Tournament Games

\begin{tabular}{|c|c|c|c|c|c|c|c|c|c|c|}
\hline \multirow[b]{3}{*}{ Game } & \multirow[b]{3}{*}{$M$} & \multirow[b]{3}{*}{$S D$} & \multirow{2}{*}{\multicolumn{2}{|c|}{$\begin{array}{l}\text { Step 1 } \\
\text { Gender }\end{array}$}} & \multicolumn{6}{|c|}{ Step 2} \\
\hline & & & & & \multicolumn{2}{|c|}{ Gf } & \multicolumn{2}{|c|}{ Prior BB Knowledge } & \multicolumn{2}{|c|}{ BB Interest } \\
\hline & & & $B$ & $s r^{2}$ & $B$ & $s r^{2}$ & $B$ & $s r^{2}$ & $B$ & $s r^{2}$ \\
\hline 1 & 1.06 & 0.73 & $-.368 * *$ & .064 & .017 & .000 & $.365 * *$ & .078 & .082 & .005 \\
\hline 2 & 1.35 & 0.69 & $-.387 * *$ & .078 & -.083 & .006 & $.290 * *$ & .054 & $.222 *$ & .043 \\
\hline 3 & 1.53 & 0.56 & $-.213^{*}$ & .026 & -.010 & .000 & .101 & .007 & $.337 * *$ & .108 \\
\hline 4 & 1.12 & 0.56 & $-.300 * *$ & .040 & -.049 & .002 & $.263 * *$ & .038 & $.184 *$ & .025 \\
\hline 5 & 1.88 & 0.38 & -.103 & .018 & .036 & .004 & .028 & .002 & .063 & .011 \\
\hline Overall & 6.94 & 2.20 & $-1.371 * *$ & .096 & -.089 & .001 & $1.046^{* *} *$ & .070 & $.888 * *$ & .068 \\
\hline
\end{tabular}

Note-Michigan State versus 1 (Alabama State), 2 (Fresno State), 3 (Gonzaga), 4 (Temple), and 5 (Arizona). Overall $=\operatorname{Sum}(1-5)$. $B$, unstandardized regression coefficient; $s r^{2}$, squared semipartial correlation. $* p<.05 . \quad * * p<.01$. 
(Michigan State vs. other NCAA) was $\chi^{2}(194)=344.84$, $\chi^{2} / d f=1.78, C F I=.94, N N F I=.93$, SRMR $=.06$. The improvement in fit relative to Model 2 was significant $\left[\Delta \chi^{2}(5)=18.89, p<.01\right]$. However, because the correlation between the two people/events variables exceeded one $(r=1.08)$, I considered Model 2 the most plausible model (see Table 6 for the factor loadings).

I also compared two possible criterion-side measurement models (see Table 5). The fit of a model (Model 4) with a single variable for new people/events knowledge was $\chi^{2}(9)=30.49, \chi^{2} / d f=3.39, C F I=.98, N N F I=.97$, $S R M R=.02$. The fit of a model (Model 5) with two new knowledge variables (Michigan State vs. other NCAA) was $\chi^{2}(8)=22.87, \chi^{2} / d f=2.86, C F I=.99, N N F I=.98$, $S R M R=.02$. The improvement in fit relative to Model 4 was slight but significant $\left[\chi^{2}(1)=7.62, p<.01\right]$. However, the correlation between the two variables was also very high $(r=.96)$. In fact, the variance inflation factor (i.e., the ratio of either variable's total variance to its unique variance) exceeded an acceptable level of 10 (i.e., $1 / 1-.96^{2}=12.5$ ), suggesting that multicollinearity would be a problem if both new knowledge factors were included in the structural equation analyses described next (Kline, 1998). Therefore, I considered Model 4 the most plausible model; loadings of the observed variables on the single latent variable were very high, ranging from .85 to .90 .

The second step in the structural equation modeling was to estimate the relations among the latent variables and gender in a structural equation model. Gender was an observed variable in this model $($ male $=0$ and female $=1)$. The fit of the model shown in Figure 1 was $\chi^{2}(264)=$ 567.64, $\chi^{2} / d f=2.15, C F I=.90, N N F I=.89, S R M R=$ .06. (As is shown in Figure 1, both significant and nonsignificant paths are in the model.) The major results can be summarized as follows. There was an effect of basketball interest on the square root of basketball exposure (.74) and an effect of the latter on new people/events knowledge (.31). Moreover, there were effects of both prior basketball knowledge variables on basketball interest-people/ events (.55) and rules/regulations (.24). Thus, as was predicted, there was an indirect effect of prior basketball knowledge on new basketball knowledge, via basketball interest and basketball exposure. However, there also was a direct effect of prior basketball knowledge on new basketball knowledge, and this effect was specific to type of prior knowledge. That is, there was an effect of prior people/ events knowledge on new basketball knowledge (.62), but a negligible effect (.04) of prior rules/regulations knowledge. By contrast, the effect of Gf on new basketball knowledge (.07) was small, as were its effects on both prior basketball knowledge variables - rules/regulations (.18) and people/events (.08). Finally, gender differences in new basketball knowledge were almost completely accounted for by prior basketball knowledge. In other words, there was an effect of gender on prior people/events $(-.54)$ and prior rules/regulations (-.57) knowledge, but there was no direct effect of gender on new basketball knowledge (-.03). Overall, the predictor variables accounted for nearly $90 \%$ of the variance in new basketball knowledge $\left(1-.32^{2}=.899\right)$.

\section{DISCUSSION}

What accounts for individual differences in domain knowledge? The results of this study suggest that interest in a domain is one important explanatory construct. That is, there was an indirect effect of basketball interest on new basketball knowledge, via basketball exposure. Although this finding should be interpreted cautiously given that basketball interest and new basketball knowledge were assessed at the same time in this study, it supports the hypothesis that interests contribute to knowledge acquisition (e.g., Alexander et al., 1994; Alexander, Kulikowich, \& Sharon, 1995; Rolfhus \& Ackerman, 1996, 1999). Furthermore, prior basketball knowledge had an effect on basketball interest: The participants high in prior basketball knowledge reported greater interest in basketball during the acquisition interval than did the participants low in prior basketball knowledge. Taken together, these results suggest that individual differences in newly acquired domain knowledge arise from a process involving interest and knowledge, at least in part. That is, as a person's interest in a domain increases, his or her knowledge of that domain increases through engagement in domain-relevant activities. In turn, as a person's knowledge of a domain increases, his or her interest in that domain increases, leading to additional exposure and, thereby, additional knowledge acquisition. The results are also consistent with the hypothesis that interest and exposure factors may contribute to gender differences in domain knowledge (e.g., Ackerman et al., 2001).

Independent of the combined influence of basketball interest and exposure, there was a direct effect of prior basketball knowledge on new basketball knowledge.

Table 5

Fit Statistics for Measurement Models

\begin{tabular}{lccccccc}
\hline Model & $\chi^{2}$ & $d f$ & $\chi^{2} / d f$ & $C F I$ & $N N F I$ & $S R M R$ & $\Delta \chi^{2} / \Delta d f$ \\
\hline Predictor & & & & & & & \\
1 & 451.69 & 203 & 2.23 & .91 & .90 & .06 & - \\
2 & 363.73 & 199 & 1.83 & .93 & .91 & .06 & $87.96 / 4(p<.001)$ \\
3 & 344.84 & 194 & 1.78 & .94 & .93 & .06 & $18.89 / 5(p<.01)$ \\
Criterion & & & & & & & - \\
4 & 30.49 & 9 & 3.39 & .98 & .97 & .02 & -02 \\
5 & 22.87 & 8 & 2.86 & .99 & .98 & .02 & $7.62 / 1(p<.01)$ \\
\hline
\end{tabular}




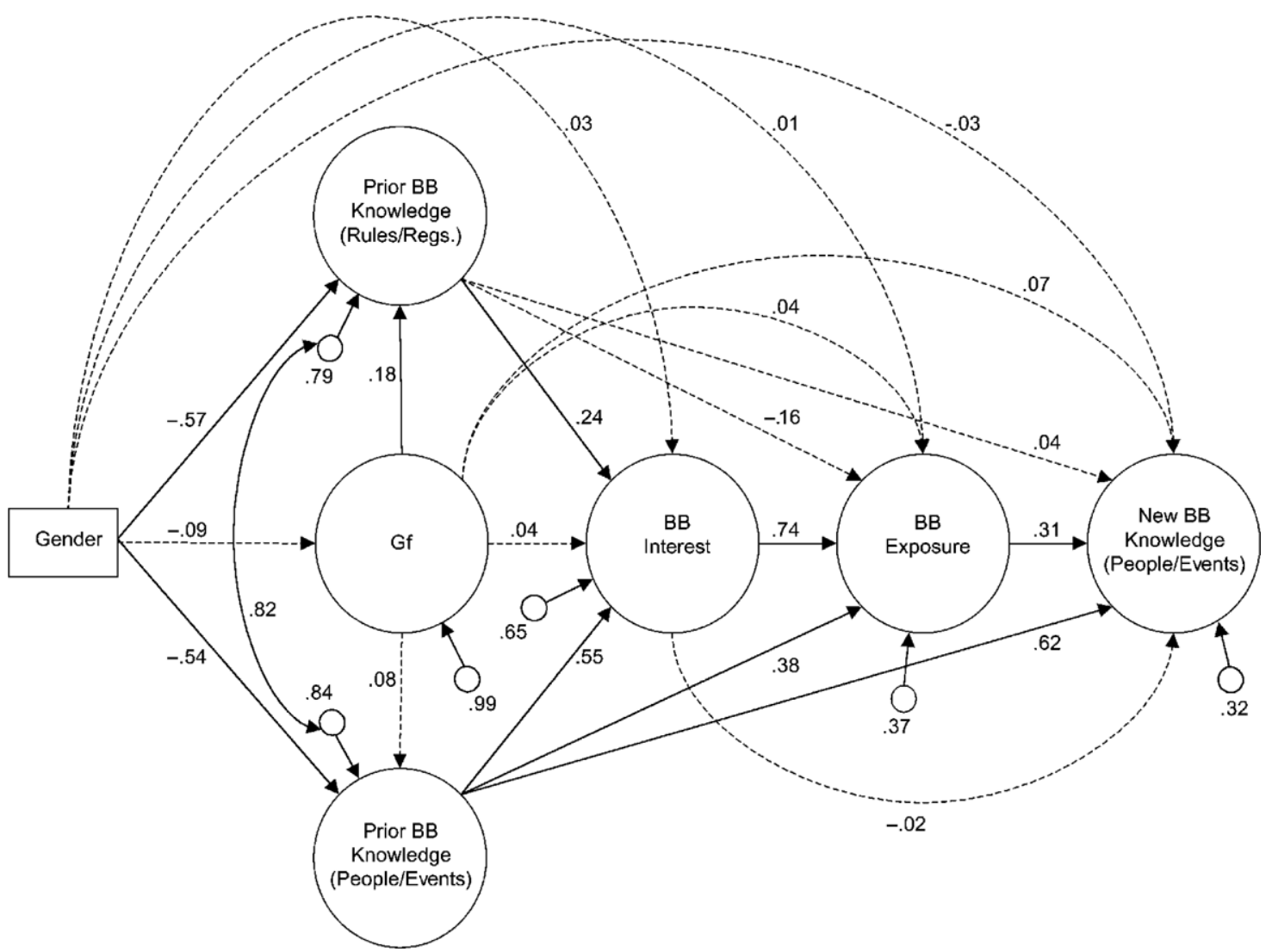

Figure 1. Structural equation model predicting new (BB) knowledge. The values adjacent to the single-headed arrows are standardized path coefficients. The values at the end of the small circles pointing to the larger circles are disturbances $(D s)$ and indicate the proportion of explained variance in the constructs (i.e., $R^{2}=1-D^{2}$ ). Solid paths are statistically significant $(p<.05)$. The value adjacent to the double-headed arrow is the correlation between the two types of prior $\mathrm{BB}$ knowledge, controlling for gender and Gf.

More specifically, structural equation modeling revealed that even though the two types of prior basketball knowledge were strongly correlated $(r=.82)$, only prior people/ events knowledge predicted new people/events knowledge; the effect of prior rules/regulations knowledge was near zero. This finding may reflect the action of an associative learning process in which new information (e.g., the score of a game between two teams) is associated with old information (e.g., scores of previous games between the two teams). Research supports this speculation. For example, vocabulary predicts paired-associate learning (Kyllonen \& Tirre, 1988; Kyllonen, Tirre, \& Christal, 1990; Thurstone, 1938), and paired-associate items made up of high-frequency words are easier to learn than are items made up of lower frequency words (e.g., Underwood, 1982). Furthermore, as was discussed earlier, experts have better memory for domain-relevant information, as compared with novices (e.g., Chase \& Simon, 1973). This evidence, along with the evidence reported here, suggests that one way learning occurs is through the linking of tobe-learned information with already-learned information.
More generally, this study supports the view that domain knowledge is a major determinant of complex cognition (e.g., Ackerman, 1996; Ceci, 1990; Ericsson, 1996; Hunt, 1980; Sternberg, 1997).

In contrast to the strong predictive effect of prior basketball knowledge, the effect of Gf on new basketball knowledge was negligible, and this was the case even for a subset of information to which a high percentage of the participants presumably were exposed (i.e., information about Michigan State NCAA tournament games). Given that Gf correlates positively with certain types of knowledge, what accounts for this finding? One possible explanation is restriction of range. As was mentioned, a limitation of this study is that the participants were positively selected on Gf, because measures of general aspects of intelligence correlate with scores on college entrance exams (e.g., Jensen, 1998). Consequently, correlations of Gf with new knowledge may have been attenuated. A related concern is that restriction of range may have compromised the validity of the tests of Gf, leading to inadequate assessment of the construct. It is also possible that these tests 
Table 6

Measurement Model for Predictor Variables

\begin{tabular}{|c|c|c|c|c|c|}
\hline \multirow[b]{2}{*}{ Variable } & \multirow[b]{2}{*}{ Gf } & \multicolumn{2}{|c|}{ Prior BB Knowledge } & \multirow[b]{2}{*}{ BB Interest } & \multirow[b]{2}{*}{ BB Exposure } \\
\hline & & Rules/Reg. & People/Evt. & & \\
\hline Raven's mat. $\dagger$ & .43 & & & & \\
\hline Cattell class. & .54 & & & & \\
\hline Shipley abs. & .65 & & & & \\
\hline Letter sets & .51 & & & & \\
\hline Comp. spana & .62 & & & & \\
\hline Read. span & .59 & & & & \\
\hline Prior BB Know. $1 \dagger$ & & .95 & & & \\
\hline Prior BB Know. $2 \dagger$ & & & .83 & & \\
\hline Prior BB Know. 3 & & & .90 & & \\
\hline Prior BB Know. 4 & & .86 & & & \\
\hline Prior BB Know. 5 & & & .84 & & \\
\hline Prior BB Know. 6 & & & .89 & & \\
\hline BB Int. $1 \dagger$ & & & & .89 & \\
\hline BB Int. 2 & & & & .81 & \\
\hline BB Int. 3 & & & & .87 & \\
\hline BB Int. 4 & & & & .87 & \\
\hline No. games att. $\dagger$ & & & & & .52 \\
\hline TV games $\mathrm{h} / \mathrm{wk} \dagger^{\mathrm{a}}$ & & & & & .76 \\
\hline TV other h/wk $\dagger$ & & & & & .76 \\
\hline $\operatorname{Read} \mathrm{h} / \mathrm{wk} \dagger$ & & & & & .60 \\
\hline Internet $\mathrm{h} / \mathrm{wk} \dagger$ & & & & & .67 \\
\hline Conv. h/wk $\dagger$ & & & & & .70 \\
\hline \multicolumn{6}{|c|}{ Latent Variable Correlations } \\
\hline & 1 & 2 & 3 & 4 & 5 \\
\hline Gf & - & .23 & .13 & .16 & .17 \\
\hline Rules/reg. & & - & .87 & .71 & .70 \\
\hline People/evt. & & & - & .75 & .79 \\
\hline BB int. & & & & - & .91 \\
\hline BB exp. & & & & & - \\
\hline
\end{tabular}

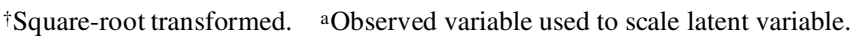

were too speeded to provide a highly reliable assessment of Gf. Nevertheless, positive correlations between Gf and measures of general or academic knowledge have been observed many times in studies in which similar Gf tests were administered to college student samples (see, e.g., Ackerman et al., 2001; Rolfhus \& Ackerman, 1999; Stanovich \& Cunningham, 1993). As will be discussed below, this suggests that the failure to observe significant correlations between Gf and knowledge may have more to do with the type of knowledge measured in this study than with characteristics of the participants and materials in this study. Moreover, severe restriction of range would have produced low reliability in the Gf variables, thereby preventing them from correlating with other variables (including each other). This was not the case.

Another possible explanation is that aspects of Gf may be involved in knowledge acquisition within some domains, but not within others. To illustrate, people may acquire knowledge about "academic" topics (e.g., history, literature, geography) typically covered on tests of Gc through reading, which is believed to require working memory. That is, numerous researchers have reported that working memory correlates positively with comprehension (see Daneman \& Merikle, 1996, for a meta-analysis). By contrast, acquisition of knowledge in other domains may occur primarily through activities that place less of a demand on Gf (e.g., watching television). Furthermore, it could be that Gf is involved in certain types of learning, but not in others. One might suspect, for example, that Gf would play a greater role in learning how to solve complex problems in a physics course than in the sort of associative learning that might be involved in remembering the outcome of a basketball game. And in fact, Ackerman and colleagues (e.g., Ackerman, 2000; Ackerman et al., 2001; Rolfhus \& Ackerman, 1996, 1999) observed positive correlations of $\mathrm{Gf}$ with knowledge of various domains in which reasoning and problem-solving processes might be expected to play an important role in learning (e.g., physics). Furthermore, Schweizer and Koch (2001) recently observed a stronger correlation of Gf with performance in a complex learning task, in which the goal was to infer rules governing series of symbols, than with performance in an associative learning task, in which the goal was to learn meanings assigned to artificial words. It should be noted that the suggestion that Gf may be particularly important for learning in complex problem-solving domains runs counter to claims that general aspects of intelligence are relatively unimportant in the development of expertise (e.g., Chi, Glaser, \& Ree, 1982; see also Ericsson, Krampe, $\&$ Tesch-Römer, 1993). However, these claims are incon- 
sistent with the empirical evidence described above. In addition, there is still relatively little evidence concerning the role of intelligence in different types of learning. A goal of future research should be to investigate this issue.

Finally, it seems possible that interests may play a role in mediating the relationship between $\mathrm{Gf}$ and knowledge. Given its strong association with psychometric g (e.g., Gustafsson, 1987, 1988), Gf might be expected to correlate positively with amount of formal education. Therefore, through formal education, people with high levels of Gf may develop greater interest in topics often covered on tests of general knowledge (e.g., history, literature, science), and consequently, they may acquire more knowledge about these topics than do people with lower levels of Gf. To the extent that this is the case, interests may in part account for the correlation between Gf and knowledge of "academic" subjects. By contrast, intuition suggests that the appeal of a leisure activity such as basketball may be relatively uniform across levels of Gf. (Consistent with this intuition, in this study, correlations of basketball interest with the Gf variables were very low-average $r=$ .11.) Another goal for future research should be to use a wider range of domains to investigate whether and to what extent interests mediate the relationship between Gf and knowledge.

\section{REFERENCES}

Ackerman, P. L. (1996). A theory of adult intelligence development: Process, personality, interests, and knowledge. Intelligence, 22, 229-259. Ackerman, P. L. (2000). Domain-specific knowledge as the "dark matter" of adult intelligence: Gf/Gc, personality and interest correlates. Journals of Gerontology: Psychological Sciences, 55B, P69-P84.

Ackerman, P. L., Beier, M. E., \& Boy Le, M. O. (2002). Individualdifferences in working memory in a nomological network of cognitive and perceptual speed measures. Journal of Experimental Psychology: General, 131, 567-589.

Ackerman, P. L., Bowen, K. R., Beier, M. E., \& Kanfer, R. (2001). Determinants of individual differences and gender differences in knowledge. Journal of Educational Psychology, 93, 797-825.

Alexander, P. A., Jetton, T. L., \& Kulikowich, J. M. (1995). Interrelationship of knowledge, interest, and recall: Assessing a model of domain learning. Journal of Educational Psychology, 87, 559-575.

Alexander, P. A., Kulikowich, J. M., \& Schulze, S. K. (1994). The influence of topic knowledge, domain knowledge, and interest on the comprehension of scientific exposition. Learning \& Individual Differences, 6, 379-397.

Alexander, P. A., Kulikowich, J. M., \& Sharon, K. (1995). The influence of topic knowledge, domain knowledge, and interest on the comprehension of scientific exposition. Learning \& Individual Differences, 6, 379-397.

Allard, F., \& Starkes, J. L. (1991). Motor-skill experts in sports, dance, and other domains. In K. A. Ericsson \& J. Smith (Eds.), Toward a general theory of expertise: Prospects and limits (pp. 126-152). New York: Cambridge University Press.

BAdDEley, A. D., \& Hitch, G. J. (1974). Working memory. In G. H. Bower (Ed.), The psychology of learning and motivation (Vol. 8, pp. 47-89). New York: Academic Press.

BAHRICK,H. P. (1979). Maintenance of knowledge: Questions about memory we forgot to ask. Journal of Experimental Psychology: General, 108, 296-308.

BAHrICK, H. P. (1984). Semantic memory content in permastore: Fifty years of memory for Spanish learned in school. Journal of Experimental Psychology: General, 113, 1-29.

BAHRICK, H. P., \& HALL, L. K. (1991). Lifetime maintenance of high school mathematics content. Journal of Experimental Psychology: General, 120, 20-33.

Bahrick, H. P., \& Phelps, E (1987). Retention of Spanish vocabulary over 8 years. Journal of Experimental Psychology: Learning, Memory, \& Cognition, 13, 344-349.

Beier, M. E., \& Ackerman, P. L. (2001). Current-events knowledge in adults: An investigation of age, intelligence, and nonability determinants. Psychology \& Aging, 16, 615-628.

Britton, B. K., Stimson, M., Stennett, B., \& Gülgöz, S. (1998). Learning from instructional text: Test of an individual-differences model. Journal of Educational Psychology, 90, 476-491.

Brown, R., \& KuliK, J. (1977). Flashbulb memories. Cognition, 5, 73-99.

Cattell, R. B. (1943). The measurement of adult intelligence. Psychological Bulletin, 40, 153-193.

CAttell, R. B. (1971). Abilities: Their structure, growth, and action. Boston: Houghton Mifflin.

Cattell, R. B., \& Horn, J. L. (1978). A check on the theory of fluid and crystallized intelligence with description of new subtest designs. Journal of Educational Measurement, 15, 139-164.

CECI, S. J. (1990). On intelligence: A bioecological treatise on intellectual development. Cambridge, MA: Harvard University Press.

Chase, W. G., \& Simon, H. A. (1973). Perception in chess. Cognitive Psychology, 4, 55-81.

Chi, M. T. H., Glaser, R. \& ReE, E. (1982). Expertise in problem solving. In R. J. Sternberg (Ed.), Advances in the psychology of human intelligence (Vol. 1, pp. 7-76). Hillsdale, NJ: Erlbaum.

CoHEn, J. (1988). Statistical power analysis for the behavioral sciences (2nd ed.). Hillsdale, NJ: Erlbaum.

Cohen, J., \& Cohen, P. (1983). Applied multiple regression/correlation analysis for the behavioral sciences ( 2 nd ed.). Hillsdale, NJ: Erlbaum.

Conway, M. A., Gardiner, J. M., Perfect, T. J., Anderson, S. J., \& Cohen, G. M. (1997). Changes in memory awareness during learning: The acquisition of knowledge by psychology undergraduates. Journal of Experimental Psychology: General, 126, 393-413.

Cook, R. D. (1977). Detection of influential observations in linear regression. Technometrics, 19, 15-18.

Cronbach, L. J. (1990). Essentials of psychological testing. Boston: Addison-Wesley.

Daneman, M., \& Merikle, P. M. (1996). Working memory and language comprehension: A meta-analysis. Psychonomic Bulletin \& Review, $\mathbf{3}$, 422-433.

EgAN, D. E., \& Schwartz, B. J. (1979). Chunking in recall of symbolic drawings. Memory \& Cognition, 7, 149-158.

Ekstrom, R. B., French, J. W., Harman, H. H., \& Derman, D. (1976). Kit of factor-referenced cognitive tests. Princeton, NJ: Educational Testing Service.

Engle, R. W., \& Bukstel, L. H. (1978). Memory processes among bridge players of differing expertise. American Journal of Psychology, 91, 673-689.

Engle, R. W., Tuholski, S. W., Laughlin, J. E., \& Conway, A. R A. (1999). Working memory, short-term memory, and general Gf: A latentvariable approach. Journal of Experimental Psychology: General, 128, 309-331.

ERICSSON, K. A. (1996). The acquisition of expert performance: An introduction to some of the issues. In K. A. Ericsson (Ed.), The road to excellence: The acquisition of expert performance in the arts and sciences, sports, and games (pp. 1-50). Mahwah, NJ: Erlbaum.

ERICSSON, K. A., \& KinTSCH, W. (1995). Long-term working memory. Psychological Review, 102, 211-245.

Ericsson, K. A., Krampe, R. T., \& Tesch-Römer, C. (1993). The role of deliberate practice in the acquisition of expert performance. Psychological Review, 100, 363-406.

GuSTAFSSON, J. (1987). The hierarchical organization of cognitive abilities: Restoring general intelligence through the use of linear structural relations (LISREL). Multivariate Behavioral Research, 22, 149-171. 
GuSTAFSSON, J. (1988). Hierarchical models of individual differences in cognitive abilities. In R. J. Sternberg (Ed.), Advances in the psychology of human intelligence (Vol. 4, pp. 35-71). Hillsdale, NJ: Erlbaum.

HAMbrick, D. Z, \& ENGLE, R. W. (2002). Effects of domain knowledge, working memory capacity, and age on cognitive performance: An investigation of the knowledge-is-power hypothesis. Cognitive Psychology, 44, 339-387.

Hambrick, D. Z., Salthouse, T. A., \& Meinz, E. J. (1999). Predictors of crossword puzzle proficiency and moderators of age-cognition relations. Journal of Experimental Psychology: General, 128, 131-164.

Henmon, V. A. C. (1921). Intelligence and its measurement: A symposium. Journal of Educational Psychology, 12, 195-198.

Holland, J. (1973). Making vocational choices: A theory of careers. Englewood Cliffs, NJ: Prentice-Hall.

Horn, J. L., \& Cattell, R. B. (1966). Refinement and test of the theory of fluid and crystallized general intelligences. Journal of Educational Psychology, 57, 253-270.

Horn, J. L., \& CATTELl, R. B. (1967). Age differences in fluid and crystallized intelligence. Acta Psychologica, 26, 107-129.

Horn, J. L., \& Noll, J. (1997). Human cognitive capabilities: Gf-Gc theory. In D. P. Flanagan, J. L. Genshaft, \& P. L. Harrison (Eds.), Contemporary intellectual assessment: Theories, tests, andissues (pp. 5391). New York: Guilford.

HunT, E. B. (1980). Intelligence as an information processing concept. British Journal of Psychology, 71, 449-474.

Institute for Personality and AbILITy Testing (1973). Measuring intelligence with culture fair tests. Champaign, IL: Author.

Jensen, A. R. (1980). Bias in mental testing. New York: Free Press.

JENSEN, A. R. (1989). The relationship between learning and intelligence. Learning \& Individual Differences, 1, 37-62.

JENSEN, A. R. (1998). The g factor: The science of mental ability. Westport, CT: Praeger.

KELLOGG, R. T. (2001). Long-term working memory in text production. Memory \& Cognition, 29, 43-52.

KLINE, R. B. (1998). Principles and practice of structural equation modeling. New York: Guilford.

Kyllonen, P. C. (1996). Is working memory capacity Spearman's g? In I. Dennis \& P. Tapsfield (Eds.), Human abilities: Their nature and measurement (pp. 49-75). Mahwah, NJ: Erlbaum.

Kyllonen, P. C., \& Christal, R. E. (1990). Reasoning ability (is little more than) working memory capacity?! Intelligence, 14, 389-433.

Kyllonen, P. C., \& Stephens, D. L. (1990). Cognitive abilities as determinants of success in acquiring logic skill. Learning \& Individual Differences, 2, 129-160.

Kyllonen, P. C., \& Tirre, W. C. (1988). Individual differences in associative learning and forgetting. Intelligence, 12, 393-421.

Kyllonen, P. C., Tirre, W. C., \& Christal, R. E. (1990). Knowledge and processing speed as determinants of associative learning. Journal of Experimental Psychology: General, 120, 57-79.

McCloskey, M., Wible, C. G., \& Cohen, N. J. (1988). Is there a specific flashbulb memory mechanism? Journal of Experimental Psychology: General, 117, 171-181.

McNamara, D. S. (1998, November). Self explanation: Effects of training, prior domain knowledge, and reading skill. Poster session presented at the 29th Annual Meeting of the Psychonomic Society, Dallas.

NeISSER, U. (1978). Memory: What are the important questions? In M. M. Gruneberg, P. E. Morris, \& R. N. Sykes (Eds.), Practical aspects of memory (pp. 3-24). London: Academic Press.

Neisser, U., Winograd, E., Bergman, E. T., Schreiber, C. A., Palmer, S. E., \& Weldon, M. S. (1996). Remembering the earthquake: Direct experience vs. hearing the news. Memory, 4, 337-357.

Pedhazur, E. J. (1997). Multiple regression in behavioral research: Explanation and prediction (3rd ed.). New York: Wadsworth.

Raven, J. (1962). Advanced Progressive Matrices, Set II. London: H. K. Lewis.

Recht, D. R., \& LESLIE, L. (1988). Effect of prior knowledge on good and poor readers' memory of text. Journal of Educational Psychology, 80, 16-20.

Ree, M. J., Caretta, T. R., \& Teachout, M. S. (1995). Role of ability and prior knowledge in complex training performance. Journal of Applied Psychology, 80, 721-730.

Rolfhus, E. L., \& Ackerman, P. L. (1996). Self-report knowledge: At the crossroads of ability, interest, and personality. Journal of Educational Psychology, 88, 174-188.

Rolfhus, E. L., \& Ackerman, P. L. (1999). Assessing individual differences in knowledge: Knowledge structures and traits. Journal of Educational Psychology, 91, 511-526.

Salthouse, T. A. (1993). Speed mediation of adult age differences in cognition. Developmental Psychology, 29, 722-738.

Salthouse, T. A., \& Babcock, R. L. (1990). Decomposing adult age differences in memory. Developmental Psychology, 27, 763-776.

Schneider, W., BJorklund, D. F., \& MaIer-BrüCKner, W. (1996). The effects of expertise and IQ on children's memory: When knowledge is, and when it is not enough. International Journal of Behavior \& Human Development, 19, 773-796.

Schneider, W., Körkel, J., \& Weinert, F. E. (1989). Domain knowledge and memory performance: A comparison of high- and lowaptitude children. Journal of Educational Psychology, 81, 306-312.

Schweizer, K., \& Koch, W. (2001). A revision of Cattell's investment theory: Cognitive properties influencing learning. Learning \& Individual Differences, 13, 57-82.

Sloboda, J. A. (1976). Visual perception of musical notation: Registering pitch symbols in memory. Quarterly Journal of Experimental Psychology, 28, 1-16.

Spilich, G. J., Vesonder, G. T., Chiesi, H. L., \& Voss, J. F. (1979). Text processing of domain-related information for individuals with high and low domain knowledge. Journal of Verbal Learning \& Verbal Behavior, 22, 231-244.

Stanovich, K. E., \& Cunningham, A. E. (1992). Studying the consequences of literacy within a literate society: The cognitive correlates of print exposure. Memory \& Cognition, 20, 51-68.

Stanovich, K. E., \& Cunningham, A. E. (1993). Where does knowledge come from? Specific associations between print exposure and information acquisition. Journal of EducationalPsychology, 85, 211 229.

Sternberg, R. J. (1997). Successful intelligence. New York: Plume. Thurstone, L. L. (1938). Primary mental abilities (Psychometric Monographs No. 1). Chicago: University of Chicago Press.

UNDERWOOD, B. J. (1982). Paired associate learning: Data on pair difficulty and variables that influence difficulty. Memory \& Cognition, 10, 610-617.

Voss, J. F., Greene, T. R., Post, T. A., \& Penner, B. C. (1983). Problemsolving skill in the social sciences. In G. H. Bower (Ed.), The psychology of learning and motivation: Advances in research and theory (Vol. 17, pp. 165-213). New York: Academic Press.

WALKER, C. H. (1987). Relative importance of domain knowledge and overall aptitude on acquisition of domain-related information. Cognition \& Instruction, 4, 25-42.

West, R. F., \& Stanovich, K. E. (1991). The incidental acquisition of information from reading. Psychological Science, 2, 325-330.

Woodrow, H. (1921). Intelligence and its measurement: A symposium. Journal of Educational Psychology, 12, 207-210.

Yekovich, F. R., Walker, C. H., Ogle, L. T., \& Thompson, M. A. (1990). The influence of domain knowledge on inferencing in lowaptitude individuals. In A. C. Graesser \& G. H. Bower (Eds.), Inferences and text comprehension: The psychology of learning and motivation (Vol. 25, pp. 175-196). New York: Academic Press.

Zachary, R. A. (1986). Shipley Institute of Living Scale. Los Angeles: Western Psychological Services.

\section{NOTES}

1. The sample used in this study cannot be considered representative of the general population with respect to the range of Gf. That is, it can be assumed that the participants were positively selected on Gf, because variables that correlate with Gf (e.g., ACT scores) are used in admission decisions at Michigan State University. However, according to data provided by Michigan State, there was a wide range of scores on the ACT for 
the freshman class of 2000-2001 (of which most of the participants in this study were members). Expressed in standard units of the 2001 national sample of all ACT-tested students $(M=21.0, S D=4.7, \mathrm{~min} / \mathrm{max}=$ $0 / 36)$, the distribution of composite ACT scores $(N=6,336)$ across the range of possible scores was as follows $(z$ scores based on the national sample are in parentheses): 30-36 (2.13-3.19), 8.1\%;24-29(0.64-1.70), $47.2 \% ; 18-23(-0.64$ to 0.43$), 40.2 \% ; 12-17(-1.91$ to -0.85$)$, $4.5 \% ;<12=0 \%$. It should also be noted that Michigan State is not considered highly selective among public universities (see US News and World Report's “America's Best Colleges"). For example, in 2000-2001, a modest $24 \%$ of freshman graduated in the top $10 \%$ of their high school class.

2 . Cook's $D$ reflects the extent to which eliminating a given participant's data would change the regression coefficients substantially. A value greater than one is generally considered large and was used as the criterion for data elimination (see Cook, 1977).

3. Michigan State defeated Alabama State (69-35), Fresno State (81-65), Gonzaga (77-62), and Temple (69-62) but then lost to Arizona (80-61) in a semifinal game (the "Final Four").

4. The maximum possible correlation between two variables is the square root of the product of the reliability of the variables (Cronbach, 1990). Therefore, the Gf variables could have even correlated strongly with the new knowledge variables, given that both sets of variables generally had acceptable reliability. For example, because the reliability of Raven's Progressive Matrices was .70, it could have correlated in the range from .74 to .78 with the new knowledge variables, given that the reliability of these variables ranged from .78 to .85 (cf. Table 2).

APPENDIX

Correlations Among Untransformed Self-Report Basketball Exposure Variables

\begin{tabular}{|c|c|c|c|c|c|c|c|c|c|c|c|c|}
\hline & 1 & 2 & 3 & 4 & 5 & 6 & 7 & 8 & 9 & 10 & 11 & 12 \\
\hline 1. TV games (rs) & - & .82 & .37 & .29 & .23 & .16 & .21 & .12 & .12 & .19 & .01 & -.03 \\
\hline 2. TV games (ps) & & - & .33 & .39 & .41 & .39 & .35 & .25 & .24 & .34 & .07 & -.03 \\
\hline 3. TV other (rs) & & & - & .74 & .31 & .26 & .37 & .22 & .52 & .40 & .04 & .00 \\
\hline 4. TV other (ps) & & & & - & .34 & .32 & .71 & .74 & .40 & .62 & .16 & .00 \\
\hline 5. Read (rs) & & & & & - & .89 & .37 & .17 & .44 & .37 & .09 & -.04 \\
\hline 6. Read (ps) & & & & & & - & .38 & .18 & .39 & .34 & .05 & -.02 \\
\hline 7. Internet (rs) & & & & & & & - & .83 & .33 & .55 & .14 & .03 \\
\hline 8. Internet (ps) & & & & & & & & - & .15 & .58 & .07 & -.01 \\
\hline 9. Conversation (rs) & & & & & & & & & - & .70 & .17 & .04 \\
\hline 10. Conversation (ps) & & & & & & & & & & - & .09 & .07 \\
\hline 11. Radio (rs) & & & & & & & & & & & - & .08 \\
\hline 12. Radio ( $\mathrm{ps}$ ) & & & & & & & & & & & & - \\
\hline
\end{tabular}

Note-Variables were measured in hours per week. rs, regular season; ps, postseason.

(Manuscript received October 18, 2001; revision accepted for publication March 29, 2003.) 